\title{
Family businesses and the gender of entrepreneurship
}

Kyriakos Lingas

Correspondence: lingas@militos.org Militos Emerging Technologies \& Services, Acharnon 335, 11145 Athens, Greece

\section{Springer}

\begin{abstract}
Background: Economy, business, and entrepreneurship are related to the world of men. Home, nurturing, and the family belong to women's world, so the story goes. On the other hand, family entrepreneurship and its outcome, the family business, is probably the most traditional way of conducting business, being thus a universal phenomenon. However, in comparison to other economic and entrepreneurial activities, the field of family entrepreneurship has been only recently addressed by economists, researchers, and academicians. Family entrepreneurship as a field of inquiry is suffering the consequences of conceptual dualisms rendering 'family' and 'business', 'kinship' and 'economy,' 'private,' and 'public' as distinct social and economic spheres. To that extent, the topic lies at the 'gray zones' of scholarly inquiry, resisting clear-cut definitions and approaches.
\end{abstract}

Findings: In this paper, based on the findings of the two case-studies addressing the issues of succession, participation, and exclusion of women in family businesses, we will explore how the concept of 'gender' informs representations and practices, which reflect social attitudes - or the construction thereof - towards the 'division of labor' between men and women in the world of entrepreneurship.

Conclusions: Drawing conclusions from the analysis, we will finally stress that core notions in both academic and laymen discourse provide a fertile ground on which the cultural category of gender can be utilized in helping to consider family entrepreneurship as a good place to start with, bringing about cultural change by reckoning contesting social categories based on gender as not of a contradictory, but of a complementary nature.

Keywords: Family business, Entrepreneurship, Gender

\section{Findings}

\section{Introduction}

It is safe to say that the majority of companies and enterprises around the globe can be more or less defined as family firms. Defining family firms is an adventurous endeavor itself. As for now, there is no consensual definition available. For the purpose of this paper, it should be taken under consideration that when referring to the form of family firm, it is meant to be an enterprise/business/company involving one or more families or family members in management and control as well as in day-in-day-out procedures. Although family firms are probably the most traditional way of conducting business not only in recent times, but throughout history, the studies of family business and family entrepreneurship in general have only recently gained the status of a

(c) 2013 Lingas; licensee Springer. This is an Open Access article distributed under the terms of the Creative Commons Attribution License (http://creativecommons.org/licenses/by/2.0), which permits unrestricted use, distribution, and reproduction in any medium, provided the original work is properly cited. 
distinct academic field. This paper will briefly explore the underlying reasons for the under representation of family entrepreneurship and family business in the mainstream academia and scholarly theorizing, employing mainly the perspective of the concept of 'gender,' to highlight dualisms and stereotypes rendering 'family' and 'business,' 'kinship' and 'economy,' 'private' and 'public' as distinct fields of social and economic conduct, which are constructed around symbolic forms.

First, we will provide an outline of theoretical aspects, which were crucial in the formation of family business studies, accompanied by an approach based mainly on the analytic potential of the concept of gender as well as on studies and insights addressing, among other things, the issues of succession, participation, and exclusion in the organizational pattern of family firms. In turn, sets of representations, practices, and social attitudes towards the engendered division of labor in the world of entrepreneurial action will be summed up.

\section{The evolution of family business studies: the epistemological context}

The purpose of this overview is to look into the ways by which family business studies have been shaped in an effort to trace the genealogy of notions and connotations accompanying family firms throughout time, both within the confines of academia as well as within the business community itself. At this point, it has to be noted that this overview is being based on the evolution of educational and research programs clearly addressing family firms in the last 50 years mainly in the USA and Europe, which is an enormous task by itself. Therefore, it is stressed out that there are certain limitations in fully capturing the evolutionary chart of family business studies as well as in presenting cross-cultural aspects for the issue at hand, which would be highly welcomed, but, on the other hand, surpasses the scope and the space limits of this study.

During the pioneering efforts in studying the business model of the family firm in the first two post-war decades (the 1950s and 1960s), family businesses were connected mostly with negative connotations. One was nepotism, referring mainly to the practices of promoting kinship relations and inter-family connections at the expense of merit and personal achievements or skills to be found outside the family circles in family business management, control, and succession models. The next more important negative connotations on which this paper attempts to focus on stem from deeply rooted stereotypes, which render the space of public and, in particular, the fields of economy, economic action, and market as a masculine arena, opposed to the space of private as a feminine arena of emotions and affective behavior, nurturing, and domesticity. Thus, in terms of educational progress in the fields of management and business, the family variable - the 'soft,' 'emotion-laden,' and 'feminine' factors - in the organizational form of family firms was either nonexistent (Dyer 2003) or the one to be tamed and kept isolated in an effort to avoid entering into 'real-world' decision-making, which should not be intruded or even disrupted by 'femininity' and emotions. These attitudes towards family firms are the product of a vicious circle of conceptualizations and generalizations, which go deep into the cultural assumptions about the division of social realm in terms of public and private domains, which are symbolically affiliated with masculinity and femininity, respectively. The family, therefore, seems to serve as a refuge from the antagonistic arena of markets, economies, and work as well as a unit of reproduction both in biological terms and in terms of reintroducing those dualisms. 
Under the light of these considerations, it is of no big surprise that during that period, the aforementioned notions and connotations marking the organizational pattern of family firms were fed up into and reflected by institutional actors of the caliber of the 'United Nations' declaring as follows:

...where the family firm does play an important part in business, it is often a reflection of the economic immaturity of the population, the absence of a tradition of impersonal service in industry and the unreliability of employees who have no kinship ties to the firm. Industrial development cannot but be handicapped by inappropriate standards of economic reality (United Nations 1955:20 in Burton 1968).

Among those lines, one could easily acknowledge the main theoretical axioms of mainstream economics, echoing the voices of the discipline's founders almost two centuries ago, according to which individuals exchange, sell, and buy as a result of an innate propensity to do so. In the evolutionary course of this procedure, people created markets, institutions, and exchange media to support social life and facilitate the functioning of the whole system, which, in turn, was based around this cosmological pattern. Following personal interest and rational calculation of means and ends, individuals as maximizers of benefit engage in practices which are determined by the rules of markets, while other qualities of psychological, emotional, and cultural nature that are involved in the economic action are considered as non-relevant. Although these assumptions have been questioned and criticized from within the discipline of economics itself, they are still with us. Moreover, at this time, these assumptions were also prevalent in social theory in general, which is mainly the Parsonian model of modern society based on the dichotomy of instrumental versus affective, which in turn drives us back to the Weberian concepts of economic versus other social actions and carrying eventually the symbolic properties of 'female' versus 'male' (Weber 1964; Yanagisako 2002). At the same time, management and business studies - at least in the USA where they were blooming - have been heavily affected by these core assumptions in theorizing economy and economic action.

Summing up the dominant paradigm in approaching and theorizing the phenomenon of family firms, it is clear that it is classified along as a conceptual schema, which pervades academic, educational, and business communities, thereby positioning family business in the gray zones between emotion and reason, female and male, individual and social/collective/cultural, and eventually humanities and sciences (Jones Andrew 2005). This ambivalent stance in the formative years of family business studies has had by and largely 'short-circuiting' the basic premises on which relevant theory and methodology were built.

By the end of the 1960s and moreover during the 1970s, social sciences have been swept by theories building up around the concept of gender. This was the result of social and political unrest characterizing Western societies at the time, leading to the emergence of the feminist project. The male-centered paradigm across social theorizing has been seriously challenged, while academic inquiry and focus moved from taken-for-granted assumptions about 'sex' to the various cultural attributes assigned each time by society to the masculine and feminine. Later on, the concept of genderrefined relevant theories, pushing up front the issue of the cultural construction of 
these theoretical categories as well as the various models of female subordination and subsequent power relation patterns, were lurking behind the so far unquestioned dichotomies (Barnard and Spencer 1996).

During this period, research, training, and consultancy on family business issues took off by providing training programs for family firm owners, which are drawn mainly from the fields of law, psychology, accounting, and management. At the same time, the need for an interdisciplinary approach has been widely acknowledged.

In the upcoming years, the scope of family business studies has been expanded stressing the socioeconomic importance of family firms, assessing the historical development of family entrepreneurship, and introducing methodological tools reaching beyond, as well as challenging, the orthodox paradigms of macro- and micro-economic assumptions (Poutziouris et al. 2006). However, as it seems, the field of family business studies as well as the accepted notions about family firms in the worlds of economy and business retained much of their previous symbolic properties. This was by and largely caused by the persistence of family business scholars to 'leave' a good part of the concept of family business unexplored and unutilized - the part of family and family dynamics. The interdisciplinary approach in the theory of family business gained momentum no sooner than the mid-1990s but had not yet fully exploited the input of diverse academic fields addressing kinship; therefore, gender issues was not an easy task to undertake. It is worth noting that a very recent literary review exploring the extent to which gender issues and theories have been used in family business research found out that even mentioning of gender issues in most of the identified articles is nonexistent (Heinonen and Hytti 2011).

In the following section, we will provide data and insights resulting from short case studies done by three scholars in the field of social sciences, which show how the gender bias actually 'works' when it comes for the female members of the family to 'step forward, either in their role at the start-up phase of a family company or as possible successors/participants in the company's organizational pattern. This descriptive part will eventually lead us to a culturally constructed symbolic matrix of binary oppositions, which actually feed social practice beyond the field of economic and entrepreneurial action, into the facets of everyday life.

\section{Family firms entrepreneurial reasoning: exploring the dynamics of gender in succession and participation}

In this section we will utilize the research findings of two studies undertaken by S. Fattoum and J. Byrne in France in 2011 and by S. Yanagisako in Italy during the 1990s, both within the scope of addressing the structure and dynamics of family firms. Based on this material, we will outline the ways by which the category of gender pervades notions and supplies sets of representations are constructed around distinct symbolic operators.

The first set of case studies explores issues of gender in family business succession in France (Fattoum and Byrne 2011) The intra-family and intra-business dynamics of succession and participation in family firms is an important research topic, which, according to the researchers, has been not thoroughly addressed with regards to gender issues and implications. On the other hand, taking under consideration the points made in the previous section, succession practices among family firms offer an excellent basis 
in approaching the inner nature of gender bias as reflected in entrepreneurial reasoning and practice.

The research project scrutinized five family firms in France, exploring the underlying 'logic' behind succession models, focusing on the ways by which the issue of gender informs and shapes decisions as well as representations of 'leadership,' 'management,' 'economic action,' and business. Methodologically, the two scholars utilize a constructionist model, a model which shows how social actors - in this case fathers as family owners and sons and daughters are candidate successors - produce, internalize, communicate, and reproduce social differentiation and inequality. The issue of the exclusion of women in the family business succession has been approached within an interactive pattern of overlying notions and cultural attitudes towards the role of women in social and economic organizations. As it is evident in the results, sons seem to be preferred against daughters in the family firm succession. This was actually the case in the selected family firms in France where male descendants of the family firm founder who was also male in all of the cases took over managerial control of the firms at the expense of female descendants.

By analyzing the respondents discourse through interviewing to explore the phenomenon of excluding female offspring in family firm succession, the researchers came with a set of interlocked attitudes and practices, throwing light to the gendered nature of intra-family firm dynamics. Their main findings can be demonstrated as follows.

It seems that in all cases reviewed, the family firm as 'a matter of family life' played a crucial role in shaping the understanding of its role in the context of family life as well as in constructing representations about the specific roles of family members in this endeavor. Eventually, the involvement and exposure to everyday firm life during childhood are thus crucial in positioning male and female descendants with regard to their chances in succession procedures. Yet family socialization and firm socialization seem to differ in the cases of sons and daughters. Sons, as young boys, are encouraged to visit the family firm, thus considering it as a 'playground, which eventually fosters the development of interest for the family firm issues as they grow older. This is a practice followed by fathers and founders of the family firms in all of the cases. In contrast, daughters are 'invited' to the firm at a much later stage when the process of socialization has already laid the fundaments of the engendered roles to be followed by them. In addition, according to the male owner/founders of the investigated family firms, the selection of sons as successors is considered more or less as natural, while daughters are really considered as an after-thought.

Although sons and daughters are equally well educated even in the fields of management and business, fathers are deeply concerned about the capabilities of daughters in effectively managing the demanding tasks associated with the company. On a different plane, fathers are also willing to 'protect' their female offspring from the cruel world of having to deal with the management of a business. The case of many of the daughters having started out and running their own businesses could easily contradict and debunk this 'protectionist' mode of the fathers, but then again, as the data clearly show, most of them are involved in the so-called soft business fields of tourism, sciences, or health, which according to the fathers serve better their innate inclinations and interests.

A second set of insights revealing the role as well as the analytical dynamics of the concept of gender in theorizing family firms and entrepreneurship comes from an 
integrated study of family firms in the silk industry of Como in Italy (Yanagisako 2002). The study explores how culture - as a distinct set of notions and representation symbolically and historically constructed - mediates the processes of the production of (economical) capital in family firms. In other words, these refer to how sentiments, kinship relations, collective notions about work, success, and family are interwoven in economic and social production and reproduction.

In this case the author methodologically proceeds in cross-fertilizing founding stories of family firms and stories other members of the family tell as well as stories the official state institutions tell with regards to the founding, succession history, and timeline of the family firms in Como. The assessed data and information revealed by the respondents provide a set of key symbolic factors which give form to the widely held representations about family, entrepreneurship, economy and economic action, and male and female roles. These key symbolic factors penetrate the essence of the organizational pattern of family firms regarding the issues of start-up and founding, participation, decision-making, and succession. They can be grouped as follows.

Men are considered as the actors exploiting 'initiatives' as generators of family firms while at the same time, being the genitors of sons following and fulfilling their destiny and their families' destinies. In addition, men are endowed with strong capacity for work, enacting the concept of the 'self-made man' within the wider context of a true social destiny and driving society by the momentum and impetus of their quests. The characteristics of 'strength', 'determination', and effective use of own masculine resources are attributed to men, while women succumb to the role of accompanying men in their adventurous routes. When women, as wives, daughters, or sisters come into play in respect of their input and participation in family firms, their main contributions ranging from initial funding of the family firm to the actual involvement in company procedures are omitted in the firm stories told by men and can only be attained through a thorough investigation of the official state records.

\section{Concluding remarks}

The purpose of this paper was to exploit the theoretical 'vagueness' in scholarly addressing the organizational pattern of family businesses as an opportunity and a tool providing valuable insights on the gendered character of the concepts of business,

Table 1 Competing categories regulating entrepreneurial reasoning in family firms discourse based on the concept of 'gender'

\begin{tabular}{ll}
\hline Feminine & Masculine \\
\hline Domestic & Market-economic realm \\
Kinship & Business \\
Private & Public \\
Passive & Active \\
Soft & Strong \\
Amateurism & Professionalism \\
Diffuse & Effective \\
Self-indulgent & Determined \\
Following, supporting & Initiating, founding \\
Humanities & Sciences \\
\hline
\end{tabular}


entrepreneurship, family, and economy in general. In a much wider context, the interconnection between the evolvement of family business studies amidst the contextual paradigm of main assumptions as portrayed in economic theory, and the core notions and conceptualizations of social actors within the family business world, provide a fertile ground on which the cultural category of gender can be utilized to expose the symbolic nature among the academic and theoretical as well as the 'performing' facet of the organizational patterns of family firms.

The presented findings of the research initiatives epitomize and reaffirm the assumption of the actual involvement of cultural dimensions informed by gender in the formation of practices regulating the social and economic conduct. By deciphering these findings, we provided an outline of the symbolic categories cross-cutting entrepreneurial practices under the viewpoint of the core symbolic operator of gender (Stewart and Hitt 2010). This would result in a table demonstrating contradictory and mutually exclusive categories by which people attach meaning to their actions (Table 1).

This approach should not be considered as paying fair dues to a structuralistic model of reasoning by dividing the world into clear-cut, antagonistic camps. As it has been made evident, social actors within family firms as well as academic inquiry addressing family entrepreneurship are more or less equally influenced by this scheme. Family entrepreneurship in both academic and laymen discourse and reasoning seems to float across the interstices of a dualistic pattern informed by perceptions and representations of gender as presented in Table 1. The challenge does not lie in trying to deconstruct these dichotomies and stereotypes, pretending that they are nonexistent or suggesting that it is simply an issue of 'power' and subjugation which is all about here. However, true and commonsensical, yet much more than this, it will probably be helpful to consider a universal phenomenon of social and economic conduct - the family firm - as having a great potential in serving as a good place to start with by bringing cultural change and in showing that contesting social categories based on gender are not of a contradictory but of a complementary nature.

Competing interest

The author declares no competing interest.

Received: 29 November 2012 Accepted: 8 May 2013

Published: 21 May 2013

\section{References}

Barnard, A, \& Spencer, J (Eds.). (1996). Encyclopedia of social and cultural anthropology. New York: Routledge. Burton, B. (1968). Family firms and economic development. Southwestern Journal of Anthropology, 24(1), 1-19. Dyer, WG. (2003). The family: the missing variable in organizational research. Entrepreneurship Theory and Practice, 27(4), 401-416. Fattoum, S, \& Byrne, J. (2011). The role of gender in family firm succession: case studies from France. World Conference Proceedings 2011. International Council for Small Business (ICSB).

Heinonen, J, \& Hytti, U. (2011). Gender in family firms: a literature review. University of Turku, School of Economics, TSE Entre1, Pori Unit2.

Jones Andrew, M. (2005). The elementary structures of the family firm: an anthropological perspective. Society for Applied Anthropology, 64(3), 276-285.

Poutziouris, PZ, Smyrnios, KX, \& Sabine, KB (Eds.). (2006). Handbook of Research on Family Business. Northampton: Edward Elgar Publishing.

Stewart, A, \& Hitt, MA. (2010). The Yin and Yang of kinship and business: complementary or contradictory forces? Advances in Entrepreneurship, Firm Emergence, and Growth, 12, 3-8.

Weber, M. (1964). The theory of social and economic organization. New York: The Fress.

Yanagisako, SJ. (2002). Producing culture and capital. Family firms in Italy. Princeton: Princeton University Press.

doi:10.1186/2192-5372-2-4

Cite this article as: Lingas: Family businesses and the gender of entrepreneurship. Journal of Innovation and Entrepreneurship 2013 2:4. 